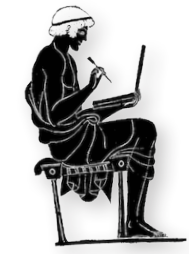

\title{
Desejo e riso: a mulher enfeitada em Aristófanes
}

Desire and laugh: the adorned woman in Aristophanes

\author{
Karen Amaral Sacconi ${ }^{1}$ \\ e-mail: karen_sacconi@hotmail.com \\ orcid: http://orcid.org/0000-0002-6673-3990
}

DOI: https://doi.org/10.25187/codex.v8i2.38322

RESUMO: A paramentação feminina é um

ABSTRACT: Female adornment is an important elemento importante das cenas de sedução que element in the scenes of seduction, which is present ocorrem em diversos gêneros da tradição poética in many genres of the Greek poetic tradition since grega desde o período arcaico. Este artigo se the Archaic period. This paper considers some of debruça sobre algumas dessas cenas na poesia épica these scenes in Homer and Hesiod and, in this de Homero e Hesíodo e, à luz desse paradigma que light, aims at analyzing how Aristophanes works se conforma, busca analisar a apropriação cômica que Aristófanes faz desses elementos em Lisístrata, Mulheres na Assembleia e Tesmoforiantes II (fragms. 332, 334 e 337).

PALAVRAS-CHAVE: Aristófanes; mulheres; comédia; sedução with this prototypical scene element in Lysistrata, Assembly of Women and Thesmophoriazusae II (frags. 332, 334 and 337).

KEYWORDS: Aristophanes; women; comedy; seduction

\footnotetext{
${ }^{1}$ Doutora em Letras Clássicas pela Universidade de São Paulo, São Paulo, Brasil.
} 
A paramentação feminina é um elemento importante das cenas de sedução que ocorrem em diversos gêneros da tradição poética grega desde o período arcaico. Uma das mais emblemáticas é a passagem da Ilíada conhecida como "núpcias de Hera e Zeus" (Il. 14.153-354), na qual a deusa planeja um engodo contra o marido: seduzi-lo, distraí-lo com o ato sexual, fazê-lo dormir após o ato e, assim, favorecer os aqueus na guerra de Troia. Ao sair do tálamo e antes de encontrar Zeus

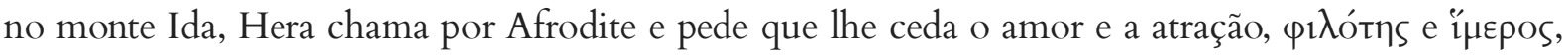
com que domina deuses e mortais. O momento que antecede esse encontro amoroso é comumente chamado toilette de Hera, quando o poeta descreve a preparação da deusa para seduzir o esposo, ao longo de 16 versos (vv. 171-88):

Lavou com ambrosia o corpo encantador, livre de toda mancha; ungiu-o com óleo ambróseo, espesso, suave, que ela mesmo perfumara. Do brônzeo piso solar de Zeus à terra e ao céu o aroma se exalava. Ungido o belo corpo, os cabelos bem penteados, entramou-os, à mão, em tranças rebrilhantes, ambrosíacas, a pender a cabeça imortal, lindas. Peplo divino-ambróseo - Atena o tecera em dedáleos recamos -, vestiu-o; broches dourados prenderam-no ao colo. Cingiu cinto ornado de cem franjas; nos lóbos bem-furados pôs um par de brincos de três gemas, amoras cintilantes quase. Toda-graça, esplendia. Um véu, novo, cobriu-lhe a divina cabeça, belo, claro, um sol.

Aos pés que reluziam atou belas sandálias.

Depois de se enfeitar com todos os adornos, deixou o tálamo e chamou por Afrodite ${ }^{2}$

\footnotetext{
${ }^{2}$ Tradução de Haroldo de Campos (São Paulo: Editora Arx, 2003).
} 
Do banho ao calçar dos pés, sete itens são elencados: óleo perfumado, peplo, broches dourados, cinto ornado com franjas, brincos de três gemas, véu e sandálias. A bela visão é resumida na expressão

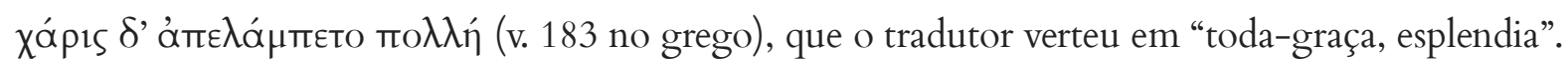

Outro exemplo oriundo da poesia épica é a ornamentação de Pandora, que ocorre logo após ela ter sido plasmada, como se fosse a etapa subsequente ao processo de criação da primeira mulher. O episódio é narrado em dois momentos na poesia de Hesíodo: Os trabalhos e os dias (vv. 6976) e Teogonia (vv. 573-584). Nessa última passagem, antes que Pandora seja enviada ao mundo dos mortais, são descritas, ao longo de 12 versos, suas vestes, véu, coroa de flores e coroa de ouro - esta, finamente trabalhada por Hefesto, é detalhada em uma pequena écfrase -, e expressões semelhantes à que destacamos em Homero exprimem o espírito da cena em Hesíodo: $\theta \alpha \tilde{u} \mu \alpha$ i $\delta$ Éo $\theta \alpha$, "prodígio aos

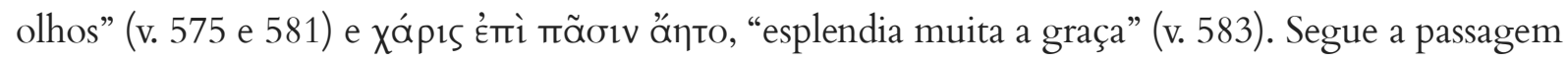
(570-587):

E criou já ao invés do fogo um mal aos homens: plasmou-o da terra o ínclito Pés-tortos como virgem pudente, por desígnios do Cronida; cingiu e adornou-a a Deusa Atena de olhos glaucos com vestes alvas, compôs um véu laborioso descendo-lhe da cabeça, prodígio aos olhos, ao redor coroa de flores novas da relva sedutora lhe pôs na fronte Palas Atena e ao redor da cabeça pôs uma coroa de ouro, quem a fabricou: o ínclito Pés-tortos lavrando-a nas mãos, agradando a Zeus pai, e muitos lavores nela gravou, prodígio aos olhos, das feras que a terra e o mar nutrem muitas ele pôs muitas ali (esplendia muita a graça) prodigiosas iguais às que vivas têm voz. Após ter criado belo o mal ao invés de um bem levou-a lá onde eram outros Deuses e homens adornada pela dos olhos glaucos e do pai forte ${ }^{3}$.

Sem perder de vista os modelos provenientes da poesia épica, este artigo debruça-se sobre passagens da comédia de Aristófanes em que personagens femininas adornam-se com o propósito de seduzir os homens. O objetivo é pensar a multiplicidade de formas com que os adornos femininos,

\footnotetext{
${ }^{3}$ Tradução de Jaa Torrano (São Paulo: Iluminuras, 2003).
} 
elemento paradigmático desse tipo de $\operatorname{cena}^{4}$, são apropriados pelo poeta cômico. São analisadas passagens de três comédias: Lisístrata (vv. 42-53; 148-53 e 870-951), Mulheres na Assembleia (vv. 877-1112) e Tesmoforiantes II, que nos chegou em estado fragmentário (fragms. 332, 334 e 337).

$\mathrm{Na}$ cena inicial de Lisístrata, quando a heroína, planejando pôr fim à guerra entre Atenas e Esparta, chefia uma reunião feminina pan-helênica e declara às mulheres que, juntas, salvarão a Grécia, sua amiga Cleonice mostra-se descrente (vv. 42-8):

Mas o que de sensato e brilhante as mulheres poderiam fazer? Nós que ficamos em casa maquiladas, vestidas com o manto de cor açafrão, enfeitadas com túnicas retas cimérias e finas sandálias?

Lisístrata responde-lhe:

São essas coisas mesmas que, espero, nos salvarão: roupinhas da cor do açafrão, perfumes, sandálias finas, ruge e tunicazinhas transparentes.

A mais icônica heroína de Aristófanes, ao se preparar para o embate com o sexo oposto, investe-se da função de estrategista. Lisístrata identifica no que consiste, segundo sua visão, a força das mulheres: a sedução; bem como as armas mais adequadas à sua tropa feminina: roupas provocantes, perfumes e acessórios. A analogia entre armamento bélico e paramentos femininos fica mais clara na sequência do diálogo, no qual se nota o paralelismo entre ambos (vv. 49-53):

\author{
Cl.: E isso de que modo? \\ Li.: De modo que homem nenhum \\ contra o outro erga a lança... \\ Cl.: Já vou já lavar a túnica cor de açafrão, pelas duas deusas. \\ Li.: nem pegue o escudo... \\ Cl.: Vou vestir a minha ciméria. \\ Li.: nem o punhal. \\ Cl.: Vou comprar sandálias finas.
}

\footnotetext{
${ }^{4}$ Em seu comentário da Ilíada, a propósito das “núpcias entre Hera e Zeus”, Richard Janko (1994: 170-1) enumera o que considera serem elementos paradigmáticos das cenas de sedução: (1) motivação, (2) preparação, (3) aproximação física, (4) reação daquele que é seduzido, (5) a narrativa falsa de quem seduz, (6) o desejo da outra parte, (7) a remoção de obstáculos, (8) o intercurso sexual e o sono, (9) o despertar abrupto. A configuração desse paradigma certamente varia de um comentador para outro, mas considero que, se reduzido a uma estrutura mais sintética, a preparação para o encontro seria um elemento tão essencial quanto o próprio enlace amoroso. Interessa-nos aqui tratar do primeiro.

${ }^{5}$ São da tradução de Adriane Duarte (São Paulo: Martins Fontes, 2005) todos os excertos de Lisístrata citados neste artigo. Mantive, no entanto, os nomes gregos das personagens, ao invés da cunhagem cômica de novos nomes proposta pela tradutora, para manter a uniformidade entre o meu texto e as citações.
} 
Por fim, Lisístrata revela a tática que trará a vitória das mulheres sobre os homens, a incitação do desejo combinada com a recusa do ato sexual (vv. 148-53):

Se ficássemos dentro de casa, maquiladas, e, sob as tunicazinhas de Amorgos, nuas desfilássemos, o púbis depilado, os maridos, cheios de tesão, desejariam fazer sexo, mas se não nos aproximássemos, se nos recusássemos, negociariam a trégua rapidinho, sei bem disso.

Aristófanes se apropria daqueles que são um elemento consagrado às cenas de sedução, os adornos, e os emprega no contexto bélico ${ }^{6}$ dessa comédia, transformando ornamentos femininos em armas. A passagem evoca as preliminares do encontro amoroso: a preparação da mulher com vestimentas, acessórios e maquiagem, que, se não acontece em cena, é bem descrita pela heroína sob a forma de prescrição às suas companheiras. Depois, haverá a cena de sedução propriamente dita, o encontro entre homem e mulher, protagonizado por Cinésias e Mirrine (vv. 870-951). O que ocorre, no entanto, é o malogro do ato: Mirrine finge consentir em "furar" a greve de sexo e, depois de excitar o marido preparando o leito longamente, frustra o enlace amoroso, deixando a cena de forma abrupta. Cinésias cai na armadilha (vv. 954-5): “Ai, ai, que será de mim? Com quem vou transar, /depois de enganado pela mais bela de todas?"

A sedução e os prazeres do amor são novamente subvertidos por Aristófanes em outro dos drámata gynaikeîon. No mundo invertido de Mulheres na Assembleia, em que Praxágora, representando a classe feminina, assume o comando do Estado, inverte-se também a narrativa da sedução. Ao pôr em cena um jovem compelido ao sexo por um grupo de três velhas (vv. 877-1111) - pois a elas os rapazes deviam dar prioridade, segundo uma das novas leis promulgadas por Praxágora -, o poeta apresenta comicamente a sedução às avessas: no lugar da bela, maravilhosa visão ( $\theta \alpha \tilde{u} \mu \alpha$ i $\delta$ Éo $\theta \alpha ı)$ e da atração física, a cena é dominada pela aversão do jovem, que se debate diante de uma visão grotesca. As velhas, mesmo contando com a força da lei, enfeitam-se para atrair o olhar dos rapazes, cobrindo

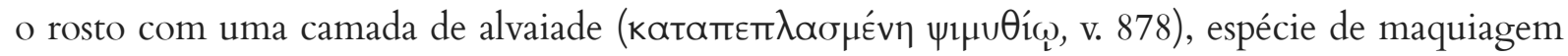
para clarear a pele, e trajando a túnica cor de açafrão (крок feminina e usada em ocasiões especiais (vv. 877-9).

\footnotetext{
' Refiro-me aqui tanto ao sentido próprio desse "contexto bélico", já que o pano de fundo da comédia é a guerra do Peloponeso, quanto ao simbólico, pois a imagem construída pelo poeta para expressar o embate entre homens e mulheres é a da guerra.
} 
Vel. 1: Então, por que os homens ainda não chegaram? Há muito já é hora! E eu aqui plantada, maquiada com alvaiade e vestida com minha túnica cor de açafrão ${ }^{7}$

A roupa e a maquiagem, que caracterizam a primeira idosa logo em sua fala inicial, mantêmse presente até o fim da cena, quando a terceira velha aparece e é descrita pelo rapaz como "macaco

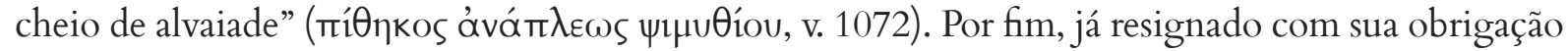
para com as três senhoras, o jovem refere-se a elas como "monstros" (Өnpíors, v. 1104):

Jo. Ó Hércules!

Ó Pã! Ó coribantes! Ó Dióscuros!

Essa desgraça é ainda mais acabada que a outra!

Mas que coisa é essa que vejo aqui?

Seria por acaso um macaco cheio de alvaiade ou uma velha ressuscitada dos mortos? (vv. 1068-73)

(...)

Por Zeus Salvador, que homem infeliz sou eu, terei de unir-me a tais monstros. (vv. 1103-4)

O tema da ornamentação feminina como elemento preliminar para a sedução está presente também, segundo penso, na comédia Tesmoforiantes II (produzida entre 415 e 406 a.C.), da qual só temos fragmentos. É importante notar que não se trata, nessa comédia, de uma revisão das Tesmoforiantes que conhecemos, mas de uma peça cômica inteiramente diferente. É possível que seja uma continuação da comédia que nos chegou, já que, se esta se passa no segundo dia do festival das Tesmofórias, aquela, Tesmoforiantes II, passa-se no terceiro dia, chamado Caligênia. É o que sugere o fragm. 331, ao revelar que a essa deusa, Caligênia, coube o prólogo da comédia ${ }^{8}$.

De modo geral, muito pouco se sabe sobre o seu enredo, porém, pode-se entrever, nos excertos que nos chegaram, algum tipo de embate entre homens e mulheres, como ocorre em Lisístrata e em Mulheres na Assembleia. Dentre os 28 fragmentos de que dispomos (frags. 331-58), o frag. 332 chama a atenção pela longa lista de artefatos femininos que apresenta, enumerados em meio a um diálogo entre duas personagens masculinas:

(A.) Navalha, espelho, tesoura, cera, sabão, peruca, bainhas, faixas para a cabeça, fitas de cabelo, ruge - é a ruína! - pó,

\footnotetext{
7 Tradução minha de todos os excertos de Mulheres na Assembleia.

8 Cf. fragm. 331. Escólio de Tesmoforiantes 298 (e à Caligênia e à Nutriz de jovens): divindade relativa a Deméter, que ele <=Aristófanes> compôs declamando o prólogo nas outras Tesmoforiantes. Para alguns estudiosos, no entanto, trata-se de um dos epítetos de Deméter. Cf. Thiercy (1997: 1.244, n. 2).
} 
perfume, pedra-pomes, faixa para os seios, faixa para o topo da cabeça, véu, ruge feito de urzela, colares, pintura para os olhos,

traje fino, heléboro, rede para os cabelos,

cinto, xale, veste delicada, veste orlada, túnica longa,

manto - fosso mortal! - manto listrado, pinça.

E eu ainda não disse o melhor. (B.) E o que é?

(A.) Brincos de furo, conjunto de gemas, brincos-argola,

adereço para pescoço, brincos-cacho,

bracelete, broches, pulseiras, colares de corrente, tornozeleira,

pedra do anel, correntes, anel, cataplasmas,

adereço para cabeça, sutiã, pênis artificial, cornalinas,

colares longos, brincos e muitas outras coisas, as quais,

falando, não conseguirias enumerar ${ }^{9}$

Até onde sabemos, os paramentos femininos são usados na comédia com dois propósitos, o de embelezar para seduzir, como foi visto nas cenas de Lisístrata e Mulheres na Assembleia, e o de disfarce para enganar, como ocorre na conhecida cena de travestimento de Tesmoforiantes, na qual o Parente de Eurípides se veste de mulher. No caso da cena em questão de Tesmoforiantes II, inclino-me, como já disse, para a primeira hipótese, apoiando-me em outro fragmento, o fragm. 337, que parece pertencer ao mesmo contexto do fragm. 332 na economia da comédia.

fragm. 337:

quão excessivos eram os acessórios delas

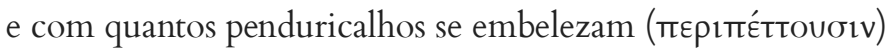

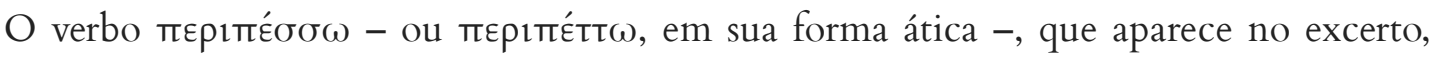
( aparência, quanto o sentido de disfarçar, camuflar. Em Aristófanes, no entanto, esse verbo, que aparece com sentido metafórico em duas das 11 comédias que nos chegaram, Pluto 159 e Vespas 668, não é usado em nenhum momento para se referir ao travestimento do homem em Tesmoforiantes. Ali, o

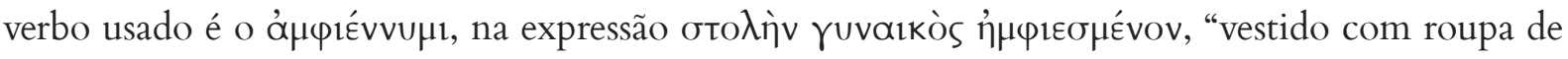
mulher" (v. 92).

Contudo, como o fragm. 337 apresenta a fala de uma personagem, e esta poderia, por ventura, enganar-se, tratando por mulheres homens travestidos; recorro, por fim, a uma informação externa ao texto, isto é, a um comentário de uma das fontes do fragm. 332. Clemente de Alexandria (séc. I d.C.), ao citar a longa lista de artefatos femininos, assim diz: "Se já me canso de dizer a enorme quantidade de ornamentos, admira-me como as mulheres não se envergonham carregando tamanho

\footnotetext{
9 Tradução minha de todos os fragmentos de Tesmoforiantes II.
} 
fardo". O que nos interessa aqui é menos o teor de censura do comentário e mais o fato de ele se

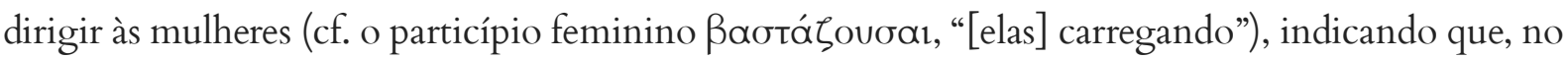
drama, as personagens que faziam uso desses ornamentos eram femininas.

É provável ainda que as personagens femininas de Tesmoforiantes II fossem mulheres casadas, não só por serem essas as que participavam do festival das Tesmofórias, mas também porque o uso de adornos nesse tipo de cena é normalmente associado à esposa ou à noiva, e não à cortesã. Laura McClure (2015: 56-7), em um artigo dedicado à caracterização de uma e de outra com vista a uma análise de Lisistrata - "Courtesans Reconsidered: Women in Aristophanes' Lysistrata" (2015) -, demonstra que, não só nessa comédia, mas também em outros gêneros poéticos, bem como em cenas pintadas na cerâmica do período clássico, os apetrechos femininos evocam um tipo de erotismo doméstico. Contrapõe-se a ele a nudez da mulher, associada à hetaíra. A mulher nua, por sua vez, está presente tanto nos vasos quanto em algumas passagens cômicas, como na própria Lisístrata, com a presença da Reconciliação (Diallagé) personificada, uma personagem muda, provavelmente uma estátua de uma jovem nua, e que é muito apreciada pelos embaixadores que contemplam a intimidade de seu corpo (vv. 1148ssq.).

Apesar de alguns itens da longa listagem do fragm. 332 não serem propriamente adornos, como o heléboro - erva medicinal usada pelas mulheres -, os cataplasmas, e o pênis artificial (o’ $\left.\lambda_{1 \sigma \beta} \sigma \varsigma\right)$, entendo que, por seu uso ser tipicamente atribuído às mulheres - este último, em especial às mulheres casadas e privadas da companhia dos maridos ${ }^{10}-$, esses objetos juntaram-se ao arsenal das vestes e enfeites com vistas ao efeito de acumulação proporcionado pela enumeração assindética. Eles comporiam uma exagerada cena de toilette feminina. Clemente de Alexandria também utiliza a

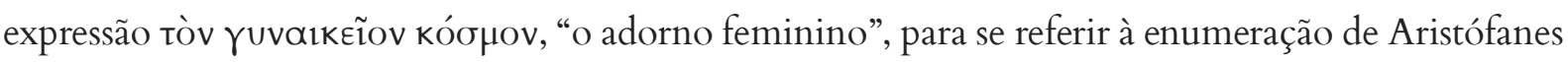
citada por ele. Por fim, que o objetivo das mulheres era mesmo se embelezarem atesta o fragm. 337 mencionado acima.

Tenho, então, que a cena de Tesmoforiantes II seja protagonizada por mulheres casadas, engajadas numa espécie de campanha na qual sua tática é, novamente, a sedução. Ao menos é isso que sugere o "armamento pesado" que empenharam, para retomar a imagem da guerra usada em Lisístrata.

A hipótese de que o embate entre os sexos em Tesmoforiantes II envolve, em alguma medida, o poder de sedução das mulheres, e seu máximo empenho em utilizá-lo, abarca ainda outro fragmento, o fragm. 334. Esse excerto nos apresenta, possivelmente, uma amostra do que teria sido a reação do lado oposto nesse embate, a reação dos homens, já que revela alguma preocupação das personagens masculinas em resistir ao esforço de sedução das mulheres:

\footnotetext{
${ }^{10}$ Cf. Lisístrata 109-10: "não vi mais nenhum consolo de oito dedos, / que nos trazia um conforto de couro". Cf. também McClure (2015: 61).
} 
fragm. 334:

não permitirei beber o vinho de Pramno, nem o de Quios, nem o tásio, nem o de Pepareto, nem outro que desperte o membro viril

Dada a escassez textual de Tesmoforiantes II, não sabemos qual o propósito da investida feminina nem o seu desenlace. Mas a imensa lista de paramentos femininos coaduna com as outras cenas analisadas neste artigo em um aspecto: em todas elas, as mulheres têm um papel ativo no jogo da sedução em relação aos homens, ainda que isso signifique, em alguns casos, fazer-se ostensivamente objeto de contemplação para os olhos masculinos, de modo a incitar seu desejo.

Aristófanes apropria-se, de maneiras diferentes, de uma cena paradigmática - que consiste, de forma sintética, na preparação da mulher com seus recursos embelezadores e o subsequente enlace amoroso - para subvertê-la comicamente de múltiplas formas. Chamo aqui subversão cômica as variantes da cena de sedução que são deformadas pelo espelho da comédia, seja pelo exagero do embelezamento, como creio ser o caso de Tesmoforiantes II; seja por inverter a lógica da atração, convertendo-a em repulsa, como em Mulheres na Assembleia; seja por transformar a sedução e a frustração do ato sexual em arma de guerra, como em Lisístrata. Em todas essas cenas, a mulher enfeitada evoca e ao mesmo tempo quebra o paradigma da cena de sedução, mas conquista o público, com o riso.

\section{Referências bibliográficas:}

ARISTÓFANES. Duas comédias: Lisístrata e Tesmoforiantes. Tradução, apresentação e notas de Adriane Duarte. São Paulo: Martins Fontes, 2005.

ARISTÓFANES. As mulheres no Parlamento. Introdução, verso do grego e notas de Maria de Fátima Sousa e Silva. Coimbra: Instituto Nacional de Investigação Científica, 1998.

ARISTOPHANES. Frogs, Assemblywomen, Wealth. Edited and translated by Jeffrey Henderson. Loeb Classical Library 180. Aristophanes vol. IV. Cambridge, MA: Harvard University Press, 1998.

ARISTOPHANES. Fragments. Edited and translated by Jeffrey Henderson. Loeb Classical Library 502. Aristophanes vol. V. Cambridge, MA: Harvard University Press, 2007.

ARISTOPHANES. Thesmophoriazusae. Edited with Introduction and Commentary by C. Austin and S. D. Olson. Oxford: Oxford University Press, 2009.

ARISTOPHANE. Théâtre complet. Textes présentés, traduits et annotés par Pascal Thiercy. Bibliothèque de la Pléiade. Paris: Éditions Gallimard, 1997.

HESÍODO. Teogonia. A origem dos deuses. Estudo e tradução de Jaa Torrano. São Paulo: Iluminuras, 2003. 
HESÍODO. Os trabalhos e os dias. Tradução, introdução e comentários: Mary de Camargo Neves Lafer. São Paulo: Iluminuras, 1996.

HOMERO. Ilíada. Tradução de Haroldo de Campos. Vol. II. São Paulo: Editora Arx, 2003.

JANKO, R. The Iliad: a Commentary. General editor: G. S. Kirk. Volume IV: books 13-16. Cambridge: Cambridge University Press, 1991.

KASSEL, R.; AUSTIN, C. Poetae Comici Graeci. Vol. III 2: Aristophanes - Testimonia et Fragmenta. Berlim, Nova Iorque: De Gruyter, 1984.

McCLURE, L. Courtesans Reconsidered: Women in Aristophanes’ Lysistrata. EuGeStA n ${ }^{\circ}$ 5, 2015. Disponível em: https://eugesta-revue.univ-lille3.fr/pdf/2015/4.McClure-Eugesta-5_2015.pdf TAAFFE. L.K. Aristophanes and Women. New York: Routledge, 1993.

$$
\text { N(3) }
$$

